\title{
Hyper-Representations by Non Square Matrices Helix-Hopes
}

\author{
T. Vougiouklis, S. Vougiouklis \\ Democritus University of Thrace, School of Education, Athens, Greece
}

Email address:

tvougiou@eled.duth.gr (T. Vougiouklis)

To cite this article:

T. Vougiouklis, S. Vougiouklis. Hyper-Representations by Non Square Matrices. Helix-Hopes. American Journal of Modern Physics. Special Issue: Issue I: Foundations of Hadronic Mathematics. Vol. 4, No. 5-1, 2015, pp. 52-58. doi: 10.11648/j.ajmp.s.2015040501.17

\begin{abstract}
Hyperstructure theory can overcome restrictions which ordinary algebraic structures have. A hyperproduct on non-square ordinary matrices can be defined by using the so called helix-hyperoperations. We define and study the helix-hyperstructures on the representations and we extend our study up to Lie-Santilli theory by using ordinary fields. Therefore the related theory can be faced by defining the hyperproduct on the extended set of non square matrices. The obtained hyperstructure is an $\mathrm{H}_{\mathrm{v}}$-algebra or an $\mathrm{H}_{\mathrm{v}}$-Lie-alebra.
\end{abstract}

Keywords: Hyperstructures, $\mathrm{H}_{\mathrm{v}}$-Structures, H/V-Structures, Hope, Helix-Hope

\section{Introduction}

We deal with the largest class of hyperstructures called $\mathrm{H}_{\mathrm{v}}$-structures introduced in 1990 [23],[26], which satisfy the weak axioms where the non-empty intersection replaces the equality.

Basic definitions:

Definitions 1.1 In a set $\mathrm{H}$ equipped with a hyperoperation, which we abbreviate it by hope $: \mathrm{H} \times \mathrm{H} \rightarrow \mathrm{P}(\mathrm{H})$, we abbreviate by WASS the weak associativity: (xy)z $\mathrm{x}(\mathrm{yz}) \neq \varnothing, \forall \mathrm{x}, \mathrm{y}, \mathrm{z} \in \mathrm{H}$ and by COW the weak commutativity: $\mathrm{xy} \cap \mathrm{yx} \neq \varnothing, \forall \mathrm{x}, \mathrm{y} \in \mathrm{H}$.

The hyperstructure $(\mathrm{H}, \cdot)$ is called $\mathrm{H}_{\mathrm{v}}$-semigroup if it is WASS and is called $\mathrm{H}_{\mathrm{v}}$-group if it is reproductive $\mathrm{H}_{\mathrm{v}}$-semigroup: $\mathrm{xH}=\mathrm{Hx}=\mathrm{H}, \forall \mathrm{x} \in \mathrm{H}$. $(\mathrm{R},+, \cdot)$ is called $\mathrm{H}_{\mathrm{v}}$-ring if $(+)$ and $(\cdot)$ are WASS, the reproduction axiom is valid for $(+)$ and $(\cdot)$ is weak distributive with respect to $(+)$ :

$$
\mathrm{x}(\mathrm{y}+\mathrm{z}) \cap(\mathrm{xy}+\mathrm{xz}) \neq \varnothing,(\mathrm{x}+\mathrm{y}) \mathrm{z} \cap(\mathrm{xz}+\mathrm{yz}) \neq \varnothing, \forall \mathrm{x}, \mathrm{y}, \mathrm{z} \in \mathrm{R} .
$$

For more definitions and applications on $\mathrm{H}_{\mathrm{v}}$-structures, see books [26],[2],[8] and the survey papers [6],[25],[30]. An extreme class is the following [26]: An $\mathrm{H}_{\mathrm{v}}$-structure is very thin iff all hopes are operations except one, with all hyperproducts singletons except only one, which is a subset of cardinality more than one. Therefore, in a very thin $\mathrm{H}_{\mathrm{v}}$-structure in a set $\mathrm{H}$ there exists a hope $(\cdot)$ and a pair $(a, b) \in \mathrm{H}^{2}$ for which $\mathrm{ab}=\mathrm{A}$, with $\operatorname{card} \mathrm{A}>1$, and all the other products, with respect to any other hopes (so they are operations), are singletons.
The fundamental relations $\beta^{*}$ and $\gamma^{*}$ are defined, in $\mathrm{H}_{\mathrm{v}}$-groups and $\mathrm{H}_{\mathrm{v}}$-rings, respectively, as the smallest equivalences so that the quotient would be group and ring, respectively [22],[23],[26],[27],[28],[35]. The way to find the fundamental classes is given by analogous theorems to the following:

Theorem 1.2 Let $(\mathrm{H}, \cdot)$ be an $\mathrm{H}_{\mathrm{v}}$-group and let us denote by $\mathrm{U}$ the set of all finite products of elements of $\mathrm{H}$. We define the relation $\beta$ in $H$ as follows: $x \beta y$ iff $\{x, y\} \subset u$ where $u \in U$. Then the fundamental relation $\beta^{*}$ is the transitive closure of the relation $\beta$.

The main point of the proof of this theorem is that $\beta$ guaranties that the following is valid: Take two elements $x, y$ such that $\{\mathrm{x}, \mathrm{y}\} \subset \mathrm{u} \in \mathrm{U}$ and any hyperproduct where one of these elements is used. Then, if this element is replaced by the other, the new hyperproduct is inside the same fundamental class where the first hyperproduct is. Therefore, if the 'hyperproducts'of the above $\beta$-classes are 'products', then, they are fundamental classes. Analogously for the $\gamma$ in $\mathrm{H}_{\mathrm{v}}$-rings.

An element is single if its fundamental class is a singleton.

Motivation for $\mathrm{H}_{\mathrm{v}}$-structures:

We know that the quotient of a group with respect to an invariant subgroup is a group.

Marty states that, the quotient of a group with respect to any subgroup is a hypergroup.

Now, the quotient of a group with respect to any partition is an $\mathrm{H}_{\mathrm{v}}$-group.

Definition 1.3 Let $(\mathrm{H}, \cdot),(\mathrm{H}, \otimes)$ be $\mathrm{H}_{\mathrm{v}}$-semigroups defined on 
the same set H. $(\cdot)$ is smaller than $(\otimes)$, and $(\otimes)$ greater than $(\cdot)$, iff there exists automorphism

$$
\mathrm{f} \in \operatorname{Aut}(\mathrm{H}, \otimes) \text { such that } \mathrm{xy} \subset \mathrm{f}(\mathrm{x} \otimes \mathrm{y}), \forall \mathrm{x} \in \mathrm{H} .
$$

Then $(\mathrm{H}, \otimes)$ contains $(\mathrm{H}, \cdot)$ and write $\cdot \leq \otimes$. If $(\mathrm{H}, \cdot)$ is structure, then it is basic and $(\mathrm{H}, \otimes)$ is an $\mathrm{H}_{\mathrm{b}}$-structure.

The Little Theorem [26]. Greater hopes of the ones which are WASS or COW, are also WASS and COW, respectively.

The fundamental relations are used for general definitions of hyperstructures. Thus, to define the general $\mathrm{H}_{\mathrm{v}}$-field one uses the fundamental relation $\gamma^{*}$ :

Definition 1.4 [23],[26],[27]. The $\mathrm{H}_{\mathrm{v}}$-ring $(\mathrm{R},+, \cdot)$ is called $\mathrm{H}_{\mathrm{v}}$-field if the quotient $\mathrm{R} / \gamma^{*}$ is a field.

Let $\omega^{*}$ be the kernel of the canonical map from $\mathrm{R}$ to $\mathrm{R} / \gamma^{*}$; then we call reproductive $\mathrm{H}_{\mathrm{v}}$-field any $\mathrm{H}_{\mathrm{v}}$-field $(\mathrm{R},+, \cdot)$ if the following axiom is valid:

$$
\mathrm{x}\left(\mathrm{R}-\omega^{*}\right)=\left(\mathrm{R}-\omega^{*}\right) \mathrm{x}=\mathrm{R}-\omega^{*}, \forall \mathrm{x} \in \mathrm{R}-\omega^{*} .
$$

From the above a new class is introduced [31],[38]:

Definition 1.5 The $\mathrm{H}_{\mathrm{v}}$-semigroup $(\mathrm{H}, \cdot)$ is called $\mathrm{h} / \mathrm{v}$-group if the $\mathrm{H} / \beta^{*}$ is a group.

Similarly the $\mathrm{h} / \mathrm{v}$-rings, h/v-fields, h/v-modulus, h/v-vector spaces etc, are defined. The $\mathrm{h} / \mathrm{v}$-group is a generalization of the $\mathrm{H}_{\mathrm{v}}$-group since the reproductivity is not necessarily valid. Sometimes a kind of reproductivity of classes is valid, i.e. if $\mathrm{H}$ is partitioned into equivalence classes $\sigma(\mathrm{x})$, then the quotient is reproductive $\mathrm{x} \sigma(\mathrm{y})=\sigma(\mathrm{xy})=\sigma(\mathrm{x}) \mathrm{y}, \forall \mathrm{x} \in \mathrm{H}[31]$.

An $\mathrm{H}_{\mathrm{v}}$-group is cyclic [17],[26], if there is element, called generator, which the powers have union the underline set, the minimal power with this property is the period of the generator. If there exists an element and a special power, the minimum one, is the underline set, then the $\mathrm{H}_{\mathrm{v}}$-group is called single-power cyclic.

To compare classes we can see on small sets. The problem of enumeration and classification of $\mathrm{H}_{\mathrm{v}}$-structures, or of classes of them, is complicate in $\mathrm{H}_{\mathrm{v}}$-structures because we have great numbers. The partial order in $\mathrm{H}_{\mathrm{v}}$-structures, introduced in [26], restrict the problem in finding the minimal $\mathrm{H}_{\mathrm{v}}$-structures, up to isomorphism. We have results recently by Bayon \& Lygeros as the following [1],[13]:

In sets with three elements: Up to isomorphism, there are 6.494 minimal $\mathrm{H}_{\mathrm{v}}$-groups. The 137 are abelians; the 6.152 are cyclic. The number of $\mathrm{H}_{\mathrm{v}}$-groups with three elements, up to isomorphism, is 1.026 .462 . The 7.926 are abelians; 1.013 .598 are cyclic. 16 are very thin. Abelian $\mathrm{H}_{\mathrm{v}}$-groups with 4 elements are, 8.028.299.905, the 7.995.884.377.

Definitions 1.6 [25],[26],[38] Let $(\mathrm{R},+, \cdot)$ be $\mathrm{H}_{\mathrm{v}}$-ring, $(\mathrm{M},+)$ be $\mathrm{COW} \mathrm{H}_{\mathrm{v}}$-group and there exists an external hope:

$$
\mathrm{R} \times \mathrm{M} \rightarrow \mathrm{P}(\mathrm{M}):(\mathrm{a}, \mathrm{x}) \rightarrow \mathrm{ax},
$$

such that, $\forall \mathrm{a}, \mathrm{b} \in \mathrm{R}$ and $\forall \mathrm{x}, \mathrm{y} \in \mathrm{M}$ we have

$$
\mathrm{a}(\mathrm{x}+\mathrm{y}) \cap(\mathrm{ax}+\mathrm{ay}) \neq \varnothing,(\mathrm{a}+\mathrm{b}) \mathrm{x} \cap(\mathrm{ax}+\mathrm{bx}) \neq \varnothing,(\mathrm{ab}) \mathrm{x} \cap \mathrm{a}(\mathrm{bx}) \neq \varnothing
$$

then $\mathrm{M}$ is called an $\mathrm{H}_{\mathrm{v}}$-module over $\mathrm{R}$. In case of an $\mathrm{H}_{\mathrm{v}}$-field $\mathrm{F}$ instead of $\mathrm{H}_{\mathrm{v}}$-ring $\mathrm{R}$, then the $\mathrm{H}_{\mathrm{v}}$-vector space is defined.

The fundamental relation $\varepsilon^{*}$ is defined to be the smallest equivalence such that the quotient $\mathrm{M} / \varepsilon^{*}$ is a module (resp., a vector space) over the fundamental ring $\mathrm{R} / \gamma^{*}$ (resp. the fundamental field $\mathrm{F} / \gamma^{*}$ ). The analogous to Theorem 1.2, is:

Theorem Let $(\mathrm{M},+)$ be $\mathrm{H}_{\mathrm{v}}$-module on the $\mathrm{H}_{\mathrm{v}}$-ring $\mathrm{R}$. Denote by $U$ the set of all expressions consisting of finite hopes either on $\mathrm{R}$ and $\mathrm{M}$ or the external hope applied on finite sets of elements of $\mathrm{R}$ and $\mathrm{M}$. Define relation $\varepsilon$ in $\mathrm{M}$ as follows: x\&y iff $\{\mathrm{x}, \mathrm{y}\} \subset \mathrm{u}$ where $\mathrm{u} \in \mathrm{U}$.

Then the relation $\varepsilon^{*}$ is the transitive closure of the relation $\varepsilon$.

Definitions 1.7 [28],[29],[38]. Let $(\mathrm{H}, \cdot)$ be hypergroupoid. We remove $h \in H$, if we consider the restriction of $(\cdot)$ in the $H-\{h\}$. We say that $h \in H$ absorbs $h \in H$ if we replace $h$ by $h$ and $\mathrm{h}$ does not appear in the structure. We say that $\mathrm{h} \in \mathrm{H}$ merges with $h \in H$, if we take as product of any $x \in H$ by $h$, the union of the results of $\mathrm{x}$ with both $\mathrm{h}, \mathrm{h}$, and consider $\mathrm{h}$ and $\mathrm{h}$ as one class, with representative $h$, therefore the element $h$ does not appeared in the hyperstructure.

Let $(\mathrm{H}, \cdot)$ be an $\mathrm{H}_{\mathrm{v}}$-group, then, if an element $\mathrm{h}$ absorbs all elements of its own fundamental class then this element becomes a single in the new $\mathrm{H}_{\mathrm{v}}$-group.

Definition 1.8 [35],[37] Let $(\mathrm{L},+)$ be $\mathrm{H}_{\mathrm{v}}$-vector space over the field $(\mathrm{F},+, \cdot), \varphi: \mathrm{F} \rightarrow \mathrm{F} / \gamma^{*}$, the canonical map and $\omega_{\mathrm{F}}=\{\mathrm{x} \in \mathrm{F}: \varphi(\mathrm{x})=0\}$, where 0 is the zero of the fundamental field $\mathrm{F} / \gamma^{*}$. Similarly, let $\omega_{\mathrm{L}}$ be the core of the canonical map $\varphi^{\prime}$ : $\mathrm{L} \rightarrow \mathrm{L} / \varepsilon^{*}$ and denote by the same symbol 0 the zero of $\mathrm{L} / \varepsilon^{*}$. Consider the bracket (commutator) hope:

$$
[,]: \mathrm{L} \times \mathrm{L} \rightarrow \mathrm{P}(\mathrm{L}):(\mathrm{x}, \mathrm{y}) \rightarrow[\mathrm{x}, \mathrm{y}]
$$

then $\mathrm{L}$ is an $\mathrm{H}_{\mathrm{v}}$-Lie algebra over $\mathrm{F}$ if the following axioms are satisfied:

(L1) The bracket hope is bilinear, i.e.

$$
\begin{gathered}
{\left[\lambda_{1} \mathrm{x}_{1}+\lambda_{2} \mathrm{x}_{2}, \mathrm{y}\right] \cap\left(\lambda_{1}\left[\mathrm{x}_{1}, \mathrm{y}\right]+\lambda_{2}\left[\mathrm{x}_{2}, \mathrm{y}\right]\right) \neq \varnothing} \\
{\left[\mathrm{x}, \lambda_{1} \mathrm{y}_{1}+\lambda_{2} \mathrm{y}\right] \cap\left(\lambda_{1}\left[\mathrm{x}_{1} \mathrm{y}_{1}\right]+\lambda_{2}\left[\mathrm{x}, \mathrm{y}_{2}\right]\right) \neq \varnothing,} \\
\forall \mathrm{x}, \mathrm{x}_{1}, \mathrm{x}_{2}, \mathrm{y}, \mathrm{y}_{1}, \mathrm{y}_{2} \in \mathrm{L} \text { and } \lambda_{1}, \lambda_{2} \in \mathrm{F}
\end{gathered}
$$$$
\text { (L2) }[\mathrm{x}, \mathrm{x}] \cap \omega_{\mathrm{L}} \neq \varnothing, \forall \mathrm{x} \in \mathrm{L}
$$

(L3) $([\mathrm{x},[\mathrm{y}, \mathrm{z}]]+[\mathrm{y},[\mathrm{z}, \mathrm{x}]]+[\mathrm{z},[\mathrm{x}, \mathrm{y}]]) \cap \omega_{\mathrm{L}} \neq \varnothing, \forall \mathrm{x}, \mathrm{y} \in \mathrm{L}$

A well known and large class of hopes is given as follows [17],[21]:

Definitions 1.9 Let $(\mathrm{G}, \cdot)$ be a groupoid, then for every $\mathrm{P} \subset \mathrm{G}$, $\mathrm{P} \neq \varnothing$, we define the following hopes, P-hopes: $\forall \mathrm{x}, \mathrm{y} \in \mathrm{G}$

$$
\begin{gathered}
P: x P y=(x P) y \cup x(P y), \\
P_{r}: x P_{r} y=(x y) P \cup x(y P), P_{1}: x P_{1} y=(P x) y \cup P(x y) .
\end{gathered}
$$

The $(\mathrm{G}, \mathrm{P}),\left(\mathrm{G}, \mathrm{P}_{\mathrm{r}}\right)$ and $\left(\mathrm{G}, \mathrm{P}_{1}\right)$ are called $\mathrm{P}$-hyperstructures. For semigroup $(\mathrm{G}, \cdot)$, we have $\mathrm{xPy}=(\mathrm{xP}) \mathrm{y} \cup \mathrm{x}(\mathrm{Py})=\mathrm{xPy}$ and $(\mathrm{G}, \mathrm{P})$ is a semihypergroup but we do not know about $\left(\mathrm{G}, \mathrm{P}_{\mathrm{r}}\right)$ and $\left(\mathrm{G}, \mathrm{P}_{1}\right)$. In some cases, depending on the choice of $P$, the $\left(\mathrm{G}, \mathrm{P}_{\mathrm{r}}\right)$ and $\left(\mathrm{G}, \mathrm{P}_{1}\right)$ can be associative or WASS.

A generalization of $\mathrm{P}$-hopes is the following [9], [10]:

Let $(\mathrm{G}, \cdot)$ be abelian group and $\mathrm{P}$ a subset of $\mathrm{G}$ with more 
than one elements. We define the hope $x_{P}$ as follows:

$$
\begin{gathered}
x \times_{P} y=x \cdot P \cdot y=\{x \cdot h \cdot y \mid h \in P\} \text { if } x \neq e \text { and } y \neq e \\
x \cdot y \text { if } x=e \text { or } y=e
\end{gathered}
$$

we call this, $\mathrm{P}_{\mathrm{e}}$-hope. The $\left(\mathrm{G}, \times_{\mathrm{P}}\right)$ is an abelian $\mathrm{H}_{\mathrm{v}}$-group.

A general definition of hopes, is the following [32],[35], [36],[37]:

Definitions 1.10 Let $\mathrm{H}$ be a set with $\mathrm{n}$ operations (or hopes) $\otimes_{1}, \otimes_{2}, \ldots, \otimes_{\mathrm{n}}$ and one map (or multivalued map) $\mathrm{f}: \mathrm{H} \rightarrow \mathrm{H}$, then $\mathrm{n}$ hopes $\partial_{1}, \partial_{2}, \ldots, \partial_{\mathrm{n}}$ on $\mathrm{H}$ are defined, called $\partial$-hopes, by putting

$$
\mathrm{x} \partial_{\mathrm{i}} \mathrm{y}=\left\{\mathrm{f}(\mathrm{x}) \otimes_{\mathrm{i}} \mathrm{y}, \mathrm{x} \otimes_{\mathrm{i}} \mathrm{f}(\mathrm{y})\right\}, \forall \mathrm{x}, \mathrm{y} \in \mathrm{H}, \mathrm{i} \in\{1,2, \ldots, \mathrm{n}\}
$$

or in case where $\otimes_{\mathrm{i}}$ is hope or $\mathrm{f}$ is multivalued map we have

$$
\mathrm{x} \partial_{\mathrm{i}} \mathrm{y}=\left(\mathrm{f}(\mathrm{x}) \otimes_{\mathrm{i}} \mathrm{y}\right) \cup\left(\mathrm{x} \otimes_{\mathrm{i}} \mathrm{f}(\mathrm{y})\right), \forall \mathrm{x}, \mathrm{y} \in \mathrm{H}, \mathrm{i} \in\{1,2, \ldots, \mathrm{n}\}
$$

Let $(G, \cdot)$ groupoid and $f_{i}: G \rightarrow G, i \in I$, set of maps on $G$. Take the map $f_{\cup}: G \rightarrow P(G)$ such that $f_{\cup}(x)=\left\{f_{i}(x) \mid i \in I\right\}$, call it the union of the $f_{i}(x)$. We call the union $\partial$-hope $(\partial)$, on $G$ if we consider the map $f_{\cup}(x)$. An important case for a map $f$, is to take the union of this with the identity id. Thus, we consider the map $\mathrm{f}=\mathrm{f} \cup(\mathrm{id})$, so $\mathrm{f}(\mathrm{x})=\{\mathrm{x}, \mathrm{f}(\mathrm{x})\}, \forall \mathrm{x} \in \mathrm{G}$, which is called b- $\partial$-hope, we denote it by $(\partial)$, so we have

$$
\mathrm{x} \partial \mathrm{y}=\{\mathrm{xy}, \mathrm{f}(\mathrm{x}) \cdot \mathrm{y}, \mathrm{x} \cdot \mathrm{f}(\mathrm{y})\}, \forall \mathrm{x}, \mathrm{y} \in \mathrm{G} .
$$

Remark. If $\otimes_{\mathrm{i}}$ is associative then $\partial_{\mathrm{i}}$ is WASS. If $\partial$ contains the operation $(\cdot)$, then it is b-operation. Moreover, if $f: G \rightarrow P(G)$ is multivalued then the b- $\partial$-hopes is defined by using the $f(x)=\{x\} \cup f(x), \forall x \in G$.

Motivation for the definition of $\partial$-hope is the derivative where only multiplication of functions is used. Therefore, for functions $\mathrm{s}(\mathrm{x}), \mathrm{t}(\mathrm{x})$, we have $\mathrm{s} \partial \mathrm{t}=\left\{\mathrm{s}^{\prime} \mathrm{t}, \mathrm{st}^{\prime}\right\},\left(^{\prime}\right)$ is the derivative.

Example. Take all polynomials of first degree $g_{i}(x)=a_{i} x+b_{i}$. We have

$$
\mathrm{g}_{1} \partial \mathrm{g}_{2}=\left\{\mathrm{a}_{1} \mathrm{a}_{2} \mathrm{x}+\mathrm{a}_{1} \mathrm{~b}_{2}, \mathrm{a}_{1} \mathrm{a}_{2} \mathrm{x}+\mathrm{b}_{1} \mathrm{a}_{2}\right\},
$$

so it is a hope in the set of first degree polynomials. Moreover all polynomials $\mathrm{x}+\mathrm{c}$, where $\mathrm{c}$ be a constant, are units.

In hyperstructures there is the uniting elements method. This is defined as follows [3],[26],[28]: Let $\mathrm{G}$ be a structure and $\mathrm{d}$ be a property, which is not valid, and $\mathrm{d}$ is described by a set of equations. Consider the partition in $\mathrm{G}$ for which it is put together, in the same class, every pair of elements that causes the non-validity of $\mathrm{d}$. The quotient $\mathrm{G} / \mathrm{d}$ is an $\mathrm{H}_{\mathrm{v}}$-structure. The quotient of $\mathrm{G} / \mathrm{d}$ by $\beta^{*}$, is a stricter structure $(\mathrm{G} / \mathrm{d}) \beta^{*}$ for which $\mathrm{d}$ is valid.

\section{Matrix Representations}

$\mathrm{H}_{\mathrm{v}}$-structures are used in Representation (abbr. by rep) Theory. Reps of $\mathrm{H}_{\mathrm{v}}$-groups can be considered either by generalized permutations or by $\mathrm{H}_{\mathrm{v}}$-matrices [18],[20],[24], [25],[26],[38]. The reps by generalized permutations can be achieved by using left or right translations. We present here the hypermatrix rep in $\mathrm{H}_{\mathrm{v}}$-structures and there exist the analogous theory for the $\mathrm{h} / \mathrm{v}$-structures.

Definitions 2.1 [20],[26] $\mathrm{H}_{\mathrm{v}}$-matrix is called a matrix with entries elements of an $\mathrm{H}_{\mathrm{v}}$-ring or $\mathrm{H}_{\mathrm{v}}$-field. The hyperproduct of two $\mathrm{H}_{\mathrm{v}}$-matrices $\mathrm{A}=\left(\mathrm{a}_{\mathrm{ij}}\right)$ and $\mathrm{B}=\left(\mathrm{b}_{\mathrm{ij}}\right)$, of type $\mathrm{m} \times \mathrm{n}$ and $\mathrm{n} \times \mathrm{r}$ respectively, is defined, in the usual manner,

$$
\mathrm{A} \cdot \mathrm{B}=\left(\mathrm{a}_{\mathrm{ij}}\right) \cdot\left(\mathrm{b}_{\mathrm{ij}}\right)=\left\{\mathrm{C}=\left(\mathrm{c}_{\mathrm{ij}}\right) \mid \mathrm{c}_{\mathrm{ij}} \in \oplus \Sigma \mathrm{a}_{\mathrm{ik}} \cdot \mathrm{b}_{\mathrm{kj}}\right\},
$$

and it is a set of $m \times r H_{v}$-matrices. The sum of products of elements of the $\mathrm{H}_{\mathrm{v}}$-field is the union of the sets obtained with all possible parentheses put on them, called n-ary circle hope on the hyperaddition.

The hyperproduct of $\mathrm{H}_{\mathrm{v}}$-matrices does not necessarily satisfy WASS.

The problem of the $\mathrm{H}_{\mathrm{v}}$-matrix representations is the following:

Definitions 2.2 Let $(\mathrm{H}, \cdot)$ be an $\mathrm{H}_{\mathrm{v}}$-group. Find an $\mathrm{H}_{\mathrm{v}}$-ring or an $\mathrm{H}_{\mathrm{v}}$-field $(\mathrm{F},+, \cdot)$, a set $\mathrm{M}_{\mathrm{R}}=\left\{\left(\mathrm{a}_{\mathrm{ij}}\right) \mid \mathrm{a}_{\mathrm{ij}} \in \mathrm{R}\right\}$ and a map

$$
\mathrm{T}: \mathrm{H} \rightarrow \mathrm{M}_{\mathrm{R}}: \mathrm{h} \rightarrow \mathrm{T}(\mathrm{h})
$$

such that

$$
\mathrm{T}\left(\mathrm{h}_{1} \mathrm{~h}_{2}\right) \cap \mathrm{T}\left(\mathrm{h}_{1}\right) \mathrm{T}\left(\mathrm{h}_{2}\right) \neq \varnothing, \forall \mathrm{h}_{1}, \mathrm{~h}_{2} \in \mathrm{H} .
$$

$\mathrm{T}$ is an $\mathrm{H}_{\mathrm{v}}$-matrix rep. If the $\mathrm{T}\left(\mathrm{h}_{1} \mathrm{~h}_{2}\right) \subset \mathrm{T}\left(\mathrm{h}_{1}\right) \mathrm{T}\left(\mathrm{h}_{2}\right), \forall \mathrm{h}_{1}, \mathrm{~h}_{2} \in \mathrm{H}$ is valid, then $\mathrm{T}$ is an inclusion rep. If $\mathrm{T}\left(\mathrm{h}_{1} \mathrm{~h}_{2}\right)=\mathrm{T}\left(\mathrm{h}_{1}\right) \mathrm{T}\left(\mathrm{h}_{2}\right)=$ $\left\{\mathrm{T}(\mathrm{h}) \mid \mathrm{h} \in \mathrm{h}_{1} \mathrm{~h}_{2}\right\}, \forall \mathrm{h}_{1}, \mathrm{~h}_{2} \in \mathrm{H}$, then $\mathrm{T}$ is a good rep and then an induced rep $\mathrm{T}^{*}$ for the hypergroup algebra is obtained. If $\mathrm{T}$ is one to one and good then it is a faithful rep.

The problem of reps is complicated because the cardinality of the product of $\mathrm{H}_{\mathrm{v}}$-matrices is very big. It can be simplified in special cases such as the following: The $\mathrm{H}_{\mathrm{v}}$-matrices are over $\mathrm{H}_{\mathrm{v}}$-fields with scalars 0 and 1 . The $\mathrm{H}_{\mathrm{v}}$-matrices are over very thin $\mathrm{H}_{\mathrm{v}}$-fields. On $2 \times 2 \mathrm{H}_{\mathrm{v}}$-matrices, since the circle hope coincides with the hyperaddition. $\mathrm{On}_{\mathrm{v}}$-fields which contain singles, then these act as absorbing.

The main theorem of reps is the following [20],[25],[26]:

Theorem 2.3 A necessary condition in order to have an inclusion rep $\mathrm{T}$ of an $\mathrm{H}_{\mathrm{v}}$-group $(\mathrm{H}, \cdot)$ by $\mathrm{n} \times \mathrm{n}_{\mathrm{v}}$-matrices over the $\mathrm{H}_{\mathrm{v}}$-rind or $\mathrm{H}_{\mathrm{v}}$-field $(\mathrm{F},+, \cdot)$ is the following:

For all classes $\beta^{*}(x), x \in H$ there must exist elements $a_{i j} \in H$, $\mathrm{i}, \mathrm{j} \in\{1, \ldots, \mathrm{n}\}$ such that

$$
\mathrm{T}\left(\beta^{*}(\mathrm{a})\right) \subset\left\{\mathrm{A}=\left(\mathrm{a}_{\mathrm{ij}}^{\prime}\right) \mid \mathrm{a}_{\mathrm{ij}}^{\prime} \in \gamma^{*}\left(\mathrm{a}_{\mathrm{ij}}\right), \mathrm{i}, \mathrm{j} \in\{1, \ldots, \mathrm{n}\}\right\}
$$

So every inclusion rep $\mathrm{T}: \mathrm{H} \rightarrow \mathrm{M}_{\mathrm{R}}: \mathrm{a} \rightarrow \mathrm{T}(\mathrm{a})=\left(\mathrm{a}_{\mathrm{ij}}\right)$ induces a homomorphic rep $\mathrm{T}^{*}$ of the group $\mathrm{H} / \beta^{*}$ over the field $\mathrm{F} / \gamma^{*}$ by putting $\mathrm{T}^{*}\left(\beta^{*}(\mathrm{a})\right)=\left[\gamma^{*}\left(\mathrm{a}_{\mathrm{ij}}\right)\right], \quad \forall \beta^{*}(\mathrm{a}) \in \mathrm{H} / \beta^{*}, \quad$ where the $\gamma^{*}\left(a_{i j}\right) \in R / \gamma^{*}$ is the ij entry of the matrix $T^{*}\left(\beta^{*}(a)\right)$. T* is called fundamental induced rep of $\mathrm{T}$.

Denote $\operatorname{tr}_{\varphi}(\mathrm{T}(\mathrm{x}))=\gamma^{*}\left(\mathrm{~T}\left(\mathrm{x}_{\mathrm{ii}}\right)\right)$ the fundamental trace, then the mapping

$$
\mathrm{X}_{\mathrm{T}}: \mathrm{H} \rightarrow \mathrm{R} / \gamma^{*}: \mathrm{x} \rightarrow \mathrm{X}_{\mathrm{T}}(\mathrm{x})=\operatorname{tr}_{\varphi}(\mathrm{T}(\mathrm{x}))=\operatorname{tr} \mathrm{T}^{*}(\mathrm{x})
$$

is called fundamental character. There are several types of traces.

Using several classes of $\mathrm{H}_{\mathrm{v}}$-structures one can face several reps [26],[29],[30],[38]: 
Definition 2.4 Let $M=M_{m \times n}$ be a module of $m \times n$ matrices over a ring $\mathrm{R}$ and take sets

$$
\mathrm{S}=\left\{\mathrm{s}_{\mathrm{k}}: \mathrm{k} \in \mathrm{K}\right\} \subseteq \mathrm{R}, \mathrm{Q}=\left\{\mathrm{Q}_{\mathrm{i}}: \mathrm{j} \in \mathrm{J}\right\} \subseteq \mathrm{M}, \mathrm{P}=\left\{\mathrm{P}_{\mathrm{i}}: \mathrm{i} \in \mathrm{I}\right\} \subseteq \mathrm{M} .
$$

Define three hopes as follows

$$
\begin{gathered}
\mathrm{S}: \mathrm{R} \times \mathrm{M} \rightarrow \mathrm{P}(\mathrm{M}):(\mathrm{r}, \mathrm{A}) \rightarrow \mathrm{rSA}=\left\{\left(\mathrm{rs}_{\mathrm{k}}\right) \mathrm{A}: \mathrm{k} \in \mathrm{K}\right\} \subseteq \mathrm{M} \\
\mathrm{Q}_{+}: \mathrm{M} \times \mathrm{M} \rightarrow \mathrm{P}(\mathrm{M}):(\mathrm{A}, \mathrm{B}) \rightarrow \mathrm{AQ}_{+} \mathrm{B}=\left\{\mathrm{A}+\mathrm{Q}_{\mathrm{j}}+\mathrm{B}: \mathrm{j} \in \mathrm{J}\right\} \subseteq \mathrm{M} \\
\mathrm{P}: \mathrm{M} \times \mathrm{M} \rightarrow \mathrm{P}(\mathrm{M}):(\mathrm{A}, \mathrm{B}) \rightarrow \mathrm{APB}=\left\{\mathrm{AP}_{\mathrm{i}}^{\mathrm{t}} \mathrm{B}: \mathrm{i} \in \mathrm{I}\right\} \subseteq \mathrm{M}
\end{gathered}
$$

Then $\left(\mathrm{M}, \mathrm{S}, \mathrm{Q}_{+}, \mathrm{P}\right)$ is a hyperalgebra over $\mathrm{R}$ called general matrix P-hyperalgebra.

The hope $\mathrm{P}$, which is a bilinear map, is a generalization of Rees' operation where, instead of one sandwich matrix, a set of sandwich matrices is used. The hope $\mathrm{P}$ is strong associative and the inclusion distributivity with respect to addition of matrices

$$
\mathrm{AP}(\mathrm{B}+\mathrm{C}) \subseteq \mathrm{APB}+\mathrm{APC} \forall \mathrm{A}, \mathrm{B}, \mathrm{C} \in \mathrm{M}
$$

is valid. Thus, $(\mathrm{M},+, \mathrm{P})$ defines a multiplicative hyperring on non-square matrices.

In a similar way a generalization of this hyperalgebra can be defined considering an $\mathrm{H}_{\mathrm{v}}$-ring or an $\mathrm{H}_{\mathrm{v}}$-field instead of a ring and using $\mathrm{H}_{\mathrm{v}}$-matrices instead of matrices.

Definition 2.5 Let $A=\left(a_{i j}\right), B=\left(b_{i j}\right) \in M_{m \times n}$, we call $(A, B)$ unitize pair of matrices if $A^{t} B=I_{n}$, where $I_{n}$ denotes the $n \times n$ unit matrix.

The following theorem can be applied in the classical theory [37],[38].

Theorem 2.6 If $\mathrm{m}<\mathrm{n}$, then there is no unitize pair.

Proof. Suppose that $\mathrm{n}>\mathrm{m}$ and that

$$
\mathrm{A}^{\mathrm{t}} \mathrm{B}=\left(\mathrm{c}_{\mathrm{ij}}\right), \mathrm{c}_{\mathrm{ij}}=\sum_{k=1}^{m} a_{i k} b_{k j}
$$

Denote by $A_{m}$ the block of the matrix $A$ such that $A_{m}=$ $\left(a_{i j}\right) \in M_{m \times m}$, i.e. we take the matrix of the first $m$ columns. Then we suppose that we have $\left(A_{m}\right)^{t} B_{m}=I_{m}$, therefore we must have $\operatorname{det}\left(A_{m}\right) \neq 0$. Now, since $n>m$, we can consider the homogeneous system with respect to the 'unknowns' $\mathrm{b}_{1 \mathrm{n}}, \mathrm{b}_{2 \mathrm{n}}, \ldots, \mathrm{b}_{\mathrm{mn}}$ :

$$
\mathrm{c}_{\mathrm{in}}=\sum_{k=1}^{m} a_{i k} b_{k n}=0 \text { for } \mathrm{i}=1,2, \ldots, \mathrm{m} .
$$

From which, we obtain that $b_{1 n}=b_{2 n}=\ldots=b_{m n}=0$, since $\operatorname{det}\left(\mathrm{A}_{\mathrm{m}}\right) \neq 0$. Using this fact on the last equation, on the same unknowns,

$$
\mathrm{c}_{\mathrm{nn}}=\sum_{k=1}^{m} a_{n k} b_{k n}=1
$$

we have $0=1$, absurd.

We recall some definitions from [18],[20],[25].

Definition 2.7 Let $(\mathrm{G}, \cdot)$ hypergroupoid, is called set of fundamental maps on $\mathrm{G}$, a set of onto maps

$$
\mathrm{Q}=\{\mathrm{q}: \mathrm{G} \times \mathrm{G} \rightarrow \mathrm{G}:(\mathrm{x}, \mathrm{y}) \stackrel{\text { onto }}{\longrightarrow} \mathrm{z} \mid \mathrm{z} \in \mathrm{xy}\} .
$$

Any subset $\mathrm{Q}_{\mathrm{s}} \subset \mathrm{Q}$ defines a hope $\left({ }_{\mathrm{s}}\right.$ ) on $\mathrm{G}$ as follows

$$
\mathrm{x}_{\mathrm{s}}^{\circ} \mathrm{y}=\{\mathrm{z} \mid \mathrm{z}=\mathrm{q}(\mathrm{x}, \mathrm{y}) \text { for some } \mathrm{q} \in \mathrm{Q}\}
$$

$\circ_{\mathrm{s}} \leq \cdot$, and $\mathrm{Q}_{\mathrm{s}} \subset \mathrm{Q}_{\mathrm{os}}$, where $\mathrm{Q}_{\mathrm{os}}$ is the set of fundamental maps with respect to $\left({ }_{\mathrm{s}}\right)$. A $\mathrm{Q}_{\mathrm{a}} \subset \mathrm{Q}$ for which every $\mathrm{Q}_{\mathrm{s}} \subset \mathrm{Q}_{\mathrm{a}}$ has $\left({ }_{\mathrm{s}}\right)$ associative (resp. WASS) is called associative (resp. WASS). A hypergroupoid $(\mathrm{G}, \cdot)$ is q-WASS if there exists an element $\mathrm{q}_{\mathrm{o}} \in \mathrm{Q}$ which defines an associative operation $\left({ }^{\circ}\right)$ in G. Remark that for $\mathrm{H}_{\mathrm{v}}$-groups we have $\mathrm{Q} \neq \varnothing$.

If $G$ is finite, $\operatorname{card} G=|G|=n$, it is q-WASS with associative $\mathrm{q}_{\mathrm{o}} \in \mathrm{Q}$. In the set $\mathrm{K}[\mathrm{G}]$ of all formal linear combinations of elements of $\mathrm{G}$ with coefficients from a field $\mathrm{K}$, we define an operation $(+)$ :

$$
\left(\mathrm{f}_{1}+\mathrm{f}_{2}\right)(\mathrm{g})=\mathrm{f}_{1}(\mathrm{~g})+\mathrm{f}_{2}(\mathrm{~g}), \forall \mathrm{g} \in \mathrm{G}, \mathrm{f}_{1}, \mathrm{f}_{2} \in \mathrm{K}[\mathrm{G}]
$$

and a hope $(*)$, the convolution,

$$
\mathrm{f}_{1} * \mathrm{f}_{2}=\left\{\mathrm{f}_{\mathrm{q}}: \mathrm{f}_{\mathrm{q}}(\mathrm{g})=\sum_{q(x, y)=g} f_{1}(x) f_{2}(y), \mathrm{q} \in \mathrm{Q}\right\} .
$$

$(\mathrm{K}[\mathrm{G}],+, *)$ is a multiplicative $\mathrm{H}_{\mathrm{v}}$-ring where the inclusion distributivity is valid, which is called hypergroupoid $\mathrm{H}_{\mathrm{v}}$-algebra.

For all $\mathrm{q} \in \mathrm{Q}, \mathrm{g} \in \mathrm{G}$, we have

$$
\begin{gathered}
|\mathrm{Q}| \leq \prod_{(x, y) i n G x G}(|x y|), 1 \leq\left|\mathrm{q}^{-1}(\mathrm{~g})\right| \leq \mathrm{n}^{2}-\mathrm{n}+1 \\
\text { and } \sum_{\operatorname{gin} G}\left|\mathrm{q}^{-1}(\mathrm{~g})\right|=\mathrm{n}^{2} .
\end{gathered}
$$

The zero map $\mathrm{f}(\mathrm{x})=0$ is a scalar element in $\mathrm{K}[\mathrm{G}]$.

In the representation theory several constructions are used, some of them are the following [26],[28],[29],[30]:

Constructions 2.8 Let $(\mathrm{H}, \cdot)$ be $\mathrm{H}_{\mathrm{v}}$-group, then for all $(\oplus)$ such that $\mathrm{x} \oplus \mathrm{y} \supset\{\mathrm{x}, \mathrm{y}\}, \forall \mathrm{x}, \mathrm{y} \in \mathrm{H}$, the $(\mathrm{H}, \oplus, \cdot)$ is an $\mathrm{H}_{\mathrm{v}}$-ring. These $\mathrm{H}_{\mathrm{v}}$-rings are called associated to $(\mathrm{H}, \cdot) \mathrm{H}_{\mathrm{v}}$-rings.

In rep theory of hypergroups, in sense of Marty where the equality is valid, there are three associated hyperrings $(\mathrm{H}, \oplus, \cdot)$ to $(\mathrm{H}, \cdot)$. The $(\oplus)$ is defined respectively, $\forall \mathrm{x}, \mathrm{y} \in \mathrm{H}$, by: type a $\mathrm{x} \oplus \mathrm{y}=\{\mathrm{x}, \mathrm{y}\}$, type $\mathrm{b} \mathrm{x} \oplus \mathrm{y}=\beta^{*}(\mathrm{x}) \cup \beta^{*}(\mathrm{y})$, type $\mathrm{c} \mathrm{x} \oplus \mathrm{y}=\mathrm{H}$.

In the above types the strong associativity and strong or inclusion distributivity, is valid.

Let $(\mathrm{H}, \cdot)$ be $\mathrm{H}_{\mathrm{V}}$-semigroup and $\left\{\mathrm{v}_{1}, \ldots, \mathrm{v}_{\mathrm{n}}\right\} \cap \mathrm{H}=\varnothing$, an ordered set, where if $\mathrm{v}_{\mathrm{i}}<\mathrm{v}_{\mathrm{j}}$, when $\mathrm{i}<\mathrm{j}$. Extend $(\cdot)$ in $\mathrm{H}_{\mathrm{n}}=\mathrm{H} \cup\left\{\mathrm{v}_{1}, \mathrm{v}_{2}, \ldots, \mathrm{v}_{\mathrm{n}}\right\}$ as follows:

$$
\begin{gathered}
\mathrm{x} \cdot \mathrm{v}_{\mathrm{i}}=\mathrm{v}_{\mathrm{i}} \cdot \mathrm{x}=\mathrm{v}_{\mathrm{i}}, \mathrm{v}_{\mathrm{i}} \cdot \mathrm{v}_{\mathrm{j}}=\mathrm{v}_{\mathrm{j}} \cdot \mathrm{v}_{\mathrm{i}}=\mathrm{v}_{\mathrm{j}}, \forall \mathrm{i}<\mathrm{j} \text { and } \\
\mathrm{v}_{\mathrm{i}} \cdot \mathrm{v}_{\mathrm{i}}=\mathrm{H} \cup\left\{\mathrm{v}_{1}, \ldots, \mathrm{v}_{\mathrm{i}-1}\right\}, \forall \mathrm{x} \in \mathrm{H}, \mathrm{i} \in\{1,2, \ldots, \mathrm{n}\} .
\end{gathered}
$$

Then $\left(\mathrm{H}_{\mathrm{n}}, \cdot\right)$ is an $\mathrm{H}_{\mathrm{V}}$-group (Attach Elements Construction). We have $\left(\mathrm{H}_{\mathrm{n}}, \cdot\right) / \beta^{*} \cong \mathrm{Z}_{2}$ and $\mathrm{v}_{\mathrm{n}}$ is single.

Some open problems arising on the topic of rep theory of hypergroups, are:

Open Problems. 
a. Find standard $\mathrm{H}_{\mathrm{v}}$-rings or $\mathrm{H}_{\mathrm{v}}$-fields to represent all $\mathrm{H}_{\mathrm{v}}$-groups by $\mathrm{H}_{\mathrm{v}}$-matrices.

b. Find reps by $\mathrm{H}_{\mathrm{v}}$-matrices over standard finite $\mathrm{H}_{\mathrm{v}}$-rings analogous to $Z_{n}$.

c. Using matrices find a generalization of the ordinary multiplication of matrices which it could be used in $\mathrm{H}_{\mathrm{v}}$-rep theory (see the helix-hope [40]).

d. Find the 'minimal' hypermatrices corresponding to the minimal hopes.

e. Find reps of special classes of hypergroups and reduce these to minimal dimensions.

\section{Helix-Hopes and Applications}

Recall some definitions from [40],[16],[11]:

Definition 3.1Let $A=\left(a_{i j}\right) \in M_{m \times n}$ be an $m \times n$ matrix and $\mathrm{s}, \mathrm{t} \in \mathrm{N}$ be natural numbers such that $1 \leq \mathrm{s} \leq \mathrm{m}, 1 \leq \mathrm{t} \leq \mathrm{n}$. Then we define a characteristic-like map cst: $\mathrm{M}_{\mathrm{m} \times \mathrm{n}} \rightarrow \mathrm{M}_{\mathrm{s} \times \mathrm{t}}$ by corresponding to the matrix $A$, the matrix Acst $=\left(a_{i j}\right)$ where $1 \leq \mathrm{i} \leq \mathrm{s}, 1 \leq \mathrm{j} \leq \mathrm{t}$. We call this map cut-projection of type st. In other words Acst is a matrix obtained from A by cutting the lines, with index greater than $\mathrm{s}$, and columns, with index greater than $\mathrm{t}$.

We can use cut-projections on several types of matrices to define sums and products, however, in this case we have ordinary operations, not multivalued.

In the same attitude we define hopes on any type of matrices:

Definition 3.2 Let $A=\left(a_{i j}\right) \in M_{m \times n}$ be an $m \times n$ matrix and $\mathrm{s}, \mathrm{t} \in \mathrm{N}$, such that $1 \leq \mathrm{s} \leq \mathrm{m}, 1 \leq \mathrm{t} \leq \mathrm{n}$. We define the mod-like map st from $M_{m \times n}$ to $M_{s \times t}$ by corresponding to $A$ the matrix $A s t=\left(a_{i j}\right)$ which has as entries the sets

$$
a_{i j}=\left\{a_{i+\kappa s, j+\lambda t} \mid 1 \leq i \leq s, 1 \leq j \leq t \text {. and } \kappa, \lambda \in N, i+\kappa s \leq m, j+\lambda t \leq n\right\} \text {. }
$$

Thus we have the map

$$
\text { st: } M_{m \times n} \rightarrow M_{s \times t}: A \rightarrow A s t=\left(a_{i j}\right) .
$$

We call this multivalued map helix-projection of type st. Thus Ast is a set of $\mathrm{s} \times \mathrm{t}$-matrices $\mathrm{X}=\left(\mathrm{x}_{\mathrm{ij}}\right)$ such that $\mathrm{x}_{\mathrm{ij}} \in \mathrm{a}_{\mathrm{ij}}, \forall \mathrm{i}, \mathrm{j}$. Obviously Amn=A. We may define helix-projections on 'matrices' of which their entries are sets.

Let $A=\left(a_{i j}\right) \in M_{m \times n}$ be a matrix and $s, t \in N$ such that $1 \leq s \leq m$, $1 \leq \mathrm{t} \leq \mathrm{n}$. Then it is clear that we can apply the helix- projection first on the columns and then on the rows, the result is the same if we apply the helix-progection on both, rows and columns. Therefore we have

$$
\text { (Asn)st }=(\text { Amt }) \text { st }=\text { Ast. }
$$

Let $A=\left(a_{i j}\right) \in M_{m \times n}$ be matrix and $s, t \in N$ such that $1 \leq s \leq m$, $1 \leq \mathrm{t} \leq \mathrm{n}$. Then if Ast is not a set of matrices but one single matrix then we call A cut-helix matrix of type $s \times t$. Thus the matrix A is a helix matrix of type $s \times t$, if Acst $=$ Ast.

Definitions 3.3 (a) Let $A=\left(a_{i j}\right) \in M_{m \times n}$ and $B=\left(b_{i j}\right) \in M_{u \times v}$ be matrices and $\mathrm{s}=\min (\mathrm{m}, \mathrm{u}), \mathrm{t}=\min (\mathrm{n}, \mathrm{u})$. We define a hope, called helix-addition or helix-sum, as follows:

$$
\begin{gathered}
\oplus: \mathrm{M}_{\mathrm{m} \times \mathrm{n}} \times \mathrm{M}_{\mathrm{u} \times \mathrm{v}} \rightarrow \mathrm{P}\left(\mathrm{M}_{\mathrm{s} \times \mathrm{t}}\right): \\
(\mathrm{A}, \mathrm{B}) \rightarrow \mathrm{A} \oplus \mathrm{B}=\mathrm{Ast}+\mathrm{Bst}=\left(\mathrm{a}_{\mathrm{ij}}\right)+\left(\mathrm{b}_{\mathrm{ij}}\right) \subset \mathrm{M}_{\mathrm{s} \times \mathrm{t}},
\end{gathered}
$$

where

$$
\left(a_{i j}\right)+\left(b_{i j}\right)=\left\{\left(c_{i j}\right)=\left(a_{i j}+b_{i j}\right) \mid a_{i j} \in a_{i j} \text { and } b_{i j} \in b_{i j}\right\} .
$$

(b) Let $A=\left(a_{i j}\right) \in M_{m \times n}$ and $B=\left(b_{i j}\right) \in M_{u \times v}$ be matrices and $\mathrm{s}=\min (\mathrm{n}, \mathrm{u})$. We define a hope, called helix-multiplication or helix-product, as follows:

$$
\begin{gathered}
\otimes: M_{m \times n} \times M_{u \times v} \rightarrow P\left(M_{m \times v}\right): \\
(A, B) \rightarrow A \otimes B=A m s \cdot B s v=\left(a_{i j}\right) \cdot\left(b_{i j}\right) \subset M_{m \times v},
\end{gathered}
$$

where

$$
\left(a_{i j}\right) \cdot\left(b_{i j}\right)=\left\{\left(c_{i j}\right)=\left(\sum a_{i t} b_{t j}\right) \mid a_{i j} \in a_{i j} \text { and } b_{i j} \in b_{i j}\right\} .
$$

The helix-addition is an external hope since it is defined on different sets and the result is also in different set. The commutativity is valid in the helix-addition. For the helixmultiplication we remark that we have $A \otimes B=A m s \cdot B s v$ so we have either $\mathrm{Ams}=\mathrm{A}$ or $\mathrm{Bsv}=\mathrm{B}$, that means that the helixprojection was applied only in one matrix and only in the rows or in the columns. If the appropriate matrices in the helix-sum and in the helix-product are cut-helix, then the result is singleton.

Remark. In $\mathrm{M}_{\mathrm{m} \times \mathrm{n}}$ the addition of matrices is an ordinary operation, therefore we are interested only in the 'product'. From the fact that the helix-product on non square matrices is defined, the definition of the Lie-bracket is immediate, therefore the helix-Lie Algebra is defined [36],[37], as well. This algebra is an $\mathrm{H}_{\mathrm{v}}$-Lie Algebra where the fundamental relation $\varepsilon^{*}$ gives, by a quotient, a Lie algebra, from which a classification is obtained.

In the following we restrict ourselves on the matrices $M_{m \times n}$ where $\mathrm{m}<\mathrm{n}$. We have analogous results in the case where $\mathrm{m}>\mathrm{n}$ and for $m=n$ we have the classical theory. In order to simplify the notation, since we have results on modm, we will use the following notation:

Notation. For given $\kappa \in \mathbb{N}-\{0\}$, we denote by $\kappa$ the remainder resulting from its division by $\mathrm{m}$ if the remainder is non zero, and $\kappa=\mathrm{m}$ if the remainder is zero. Thus a matrix

$\mathrm{A}=\left(\mathrm{a}_{\mathrm{k} \lambda}\right) \in \mathrm{M}_{\mathrm{m} \times \mathrm{n}}, \quad \mathrm{m}<\mathrm{n}$ is a cut-helix matrix if $\mathrm{a}_{\mathrm{k} \lambda}=\mathrm{a}_{\mathrm{k} \lambda}$, $\forall \kappa, \lambda \in \mathbb{N}-\{0\}$.

Moreover let us denote by $\mathrm{I}_{\mathrm{c}}=\left(\mathrm{c}_{\mathrm{\kappa} \lambda}\right)$ the cut-helix unit matrix which the cut matrix is the unit matrix $\mathrm{I}_{\mathrm{m}}$. Therefore, since $\mathrm{I}_{\mathrm{m}}=\left(\delta_{\kappa \lambda}\right)$, where $\delta_{\kappa \lambda}$ is the Kronecker's delta, we obtain that, $\forall \kappa, \lambda$, we have $\mathrm{c}_{\kappa \lambda}=\delta_{\kappa} \lambda$.

Proposition 3.4 For $\mathrm{m}<\mathrm{n}$ in $\left(\mathrm{M}_{\mathrm{m} \times \mathrm{n}}, \otimes\right)$ the cut-helix unit matrix $I_{c}=\left(c_{\kappa \lambda}\right)$, where $c_{\kappa \lambda}=\delta_{\kappa \lambda}$, is a left scalar unit and a right unit. It is the only one left scalar unit.

Proof. Let $A, B \in M_{m \times n}$ then in the helix-multiplication, since $\mathrm{m}<\mathrm{n}$, we take helix projection of the matrix $\mathrm{A}$, therefore, the result $A \otimes B$ is singleton if the matrix $A$ is a cut-helix matrix of type $m \times m$. Moreover, in order to have $A \otimes B=A m m \cdot B=B$, the matrix Amm must be the unit matrix. Consequently, $I_{c}=\left(c_{\kappa}\right)$, where $\mathrm{c}_{\kappa \lambda}=\delta_{\kappa \lambda}, \forall \kappa, \lambda \in \mathbb{N}-\{0\}$, is necessarily the left scalar unit 
element.

Now we remark that it is not possible to have the same case for the right matrix $\mathrm{B}$, therefore we have only to prove that cut-helix unit matrix $I_{c}$ is a right unit but it is not a scalar, consequently it is not unique.

Let $A=\left(a_{u v}\right) \in M_{m \times n}$ and consider the hyperproduct $A \otimes I_{c}$. In the entry $\kappa \lambda$ of this hyperproduct there are sets, for all $1 \leq \kappa \leq \mathrm{m}$, $1 \leq \lambda \leq n$, of the form

$$
\Sigma \mathrm{a}_{\mathrm{\kappa s}} \mathrm{c}_{\mathrm{s} \lambda}=\Sigma \mathrm{a}_{\mathrm{ks}} \delta_{\mathrm{s} \lambda}=\mathrm{a}_{\mathrm{\kappa} \lambda} \ni \mathrm{a}_{\mathrm{k} \lambda}
$$

Therefore $\mathrm{A} \otimes \mathrm{I}_{\mathrm{c}} \ni \mathrm{A}, \forall \mathrm{A} \in \mathrm{M}_{\mathrm{m} \times \mathrm{n}}$.

In the following examples of the helix-hope, we denote $E_{i j}$ any type of matrices which have the ij-entry 1 and in all the other entries we have 0 .

Example 3.5 [38] Consider the $2 \times 3$ matrices of the following form,

$$
\mathrm{A}_{\kappa}=\mathrm{E}_{11}+\kappa \mathrm{E}_{21}+\mathrm{E}_{22}+\mathrm{E}_{23}, \mathrm{~B}_{\mathrm{\kappa}}=\kappa \mathrm{E}_{21}+\mathrm{E}_{22}+\mathrm{E}_{23}, \forall \kappa \in \mathbb{N} \text {. }
$$

Then we obtain $A_{\kappa} \otimes A_{\lambda}=\left\{A_{\kappa+\lambda}, A_{\lambda+1}, B_{\kappa+\lambda}, B_{\lambda+1}\right\}$.

Similarly we have $\mathrm{B}_{\kappa} \otimes \mathrm{A}_{\lambda}=\left\{\mathrm{B}_{\mathrm{\kappa}+\lambda}, \mathrm{B}_{\lambda+1}\right\}, \mathrm{A}_{\kappa} \otimes \mathrm{B}_{\lambda}=\mathrm{B}_{\lambda}=\mathrm{B}_{\kappa} \otimes \mathrm{B}_{\lambda}$.

Thus $\left\{\mathrm{A}_{\kappa}, \mathrm{B}_{\lambda} \mid \kappa, \lambda \in \mathbb{N}\right\}$ becomes an $\mathrm{H}_{\mathrm{v}}$-semigroup, not COW because for $\kappa \neq \lambda$ we have $B_{\kappa} \otimes B_{\lambda}=B_{\lambda} \neq B_{\kappa}=B_{\lambda} \otimes B_{\kappa}$, however

$$
\left(\mathrm{A}_{\kappa} \otimes \mathrm{A}_{\lambda}\right) \cap\left(\mathrm{A}_{\lambda} \otimes \mathrm{A}_{\kappa}\right)=\left\{\mathrm{A}_{\kappa+\lambda}, \mathrm{B}_{\kappa+\lambda}\right\} \neq \varnothing, \forall \kappa, \lambda \in \mathbb{N} .
$$

All $B_{\lambda}$ are right absorbing and $B_{1}$ is a left scalar, because $\mathrm{B}_{1} \otimes \mathrm{A}_{\lambda}=\mathrm{B}_{\lambda+1}$ and $\mathrm{B}_{1} \otimes \mathrm{B}_{\lambda}=\mathrm{B}_{\lambda}$. The $\mathrm{A}_{0}$ is a unit.

Example 3.6 Consider the $2 \times 3$ matrices of the forms,

$$
\mathrm{A}_{\kappa \lambda}=\mathrm{E}_{11}+\mathrm{E}_{13}+\kappa \mathrm{E}_{21}+\mathrm{E}_{22}+\lambda \mathrm{E}_{23}, \forall \kappa, \lambda \in \mathbb{Z} .
$$

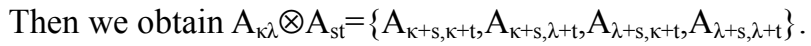

Moreover $\quad \mathrm{A}_{\mathrm{st}} \otimes \mathrm{A}_{\kappa \lambda}=\left\{\mathrm{A}_{\kappa+\mathrm{s}, \lambda+\mathrm{s}}, \mathrm{A}_{\kappa+\mathrm{s}, \lambda+\mathrm{t}}, \mathrm{A}_{\kappa+\mathrm{t}, \lambda+\mathrm{s}}, \mathrm{A}_{\kappa+\mathrm{t}, \lambda+\mathrm{t}}\right\}$, so $\mathrm{A}_{\kappa \lambda} \otimes \mathrm{A}_{\mathrm{st}} \cap \mathrm{A}_{\mathrm{st}} \otimes \mathrm{A}_{\kappa \lambda}=\left\{\mathrm{A}_{\kappa+\mathrm{s}, \lambda+\mathrm{t}}\right\}$, thus $(\otimes)$ is COW.

The helix multiplication $(\otimes)$ is associative.

Example 3.7 Consider all traceless matrices $A=\left(a_{i j}\right) \in M_{2 \times 3}$, in the sence that $a_{11}+a_{22}=0$. In this case, the cardinality of the helix-product of any two matrices is 1 , or $2^{3}$, or $2^{6}$. These correspond to the cases: $\mathrm{a}_{11}=\mathrm{a}_{13}$ and $\mathrm{a}_{21}=\mathrm{a}_{23}$, or only $\mathrm{a}_{11}=\mathrm{a}_{13}$ either only $a_{21}=a_{23}$, or if there is no restriction, respectively. For the Lie-bracket of two traceless matrices the corresponding cardinalities are up to 1 , or $2^{6}$, or $2^{12}$, respectively. We remark that, from the definition of the helix-projection, the initial $2 \times 2$, block guaranties that in the result there exists at least one traceless matrix.

From this example it is obvious the following:

Theorem 3.8 The Lie-bracket of any two traceless matrices $\mathrm{A}=\left(\mathrm{a}_{\mathrm{ij}}\right), \mathrm{B}=\left(\mathrm{b}_{\mathrm{ij}}\right) \in \mathrm{M}_{\mathrm{m} \times \mathrm{n}}, \mathrm{m}<\mathrm{n}$, contain at least one traceless matrix.

Last years hyperstructures there is a variety of applications in mathematics and in other sciences. Hyperstructures theory can now be widely applicable in industry and production, too. In several books and papers [2],[4],[5],[7],[8],[10],[12], [19],[26],[33],[39] one can find numerous applications.

The Lie-Santilli theory on isotopies was born in 1970's to solve Hadronic Mechanics problems. The original theory is reconstructed such as to admit the new matrix as left and right unit. Isofields needed in this theory correspond into the hyperstructures were introduced by Santilli and Vougiouklis in 1996 and they are called e-hyperfields [9],[14],[15],[33], [36]. The $\mathrm{H}_{\mathrm{v}}$-fields can give e-hyperfields which can be used in the isotopy theory for applications.

Definitions 3.9 A hyperstructure $(\mathrm{H}, \cdot)$ which contain a unique scalar unit e, is called e-hyperstructure, where we assume that $\forall \mathrm{x}$, there exists an inverse $\mathrm{x}^{-1}$, so $\mathrm{e} \in \mathrm{x} \cdot \mathrm{x}^{-1} \cap \mathrm{x}^{-1} \cdot \mathrm{x}$. A hyperstructure $(\mathrm{F},+, \cdot)$, where $(+)$ is an operation and $(\cdot)$ is a hope, is called e-hyperfield if the following are valid:

$(\mathrm{F},+)$ is abelian group with the additive unit $0,(\cdot)$ is WASS,

$(\cdot)$ is weak distributive with respect to $(+), 0$ is absorbing: $0 \cdot \mathrm{x}=\mathrm{x} \cdot 0=0, \forall \mathrm{x} \in \mathrm{F}$, exist a scalar unit 1 , i.e. $1 \cdot \mathrm{x}=\mathrm{x} \cdot 1=\mathrm{x}, \forall \mathrm{x} \in \mathrm{F}$, $\forall \mathrm{x} \in \mathrm{F}$ there exists unique inverse $\mathrm{x}^{-1}$, s.t. $1 \in \mathrm{X} \cdot \mathrm{x}^{-1} \cap \mathrm{x}^{-1} \cdot \mathrm{x}$.

The elements of an e-hyperfield are called e-hypernumbers. In the case that the relation: $1=\mathrm{x} \cdot \mathrm{x}^{-1}=\mathrm{x}^{-1} \cdot \mathrm{x}$, is valid, then we say that we have a strong e-hyperfield.

A general construction based on the partial ordering of the $\mathrm{H}_{\mathrm{v}}$-structures:

Construction 3.10 [6],[36], Main e-Construction. Given a group $(\mathrm{G}, \cdot)$, where e is the unit, then we define in $\mathrm{G}$, a large number of hopes $(\otimes)$ by extended $(\cdot)$, as follows:

$\mathrm{x} \otimes \mathrm{y}=\left\{\mathrm{xy}, \mathrm{g}_{1}, \mathrm{~g}_{2}, \ldots\right\}, \forall \mathrm{x}, \mathrm{y} \in \mathrm{G}-\{\mathrm{e}\}$, and $\mathrm{g}_{1}, \mathrm{~g}_{2}, \ldots \in \mathrm{G}-\{\mathrm{e}\}$

Then $(\mathrm{G}, \otimes)$ becomes an $\mathrm{H}_{\mathrm{v}}$-group, in fact is $\mathrm{H}_{\mathrm{b}}$-group which contains the $(\mathrm{G}, \cdot)$. The $\mathrm{H}_{\mathrm{v}}$-group $(\mathrm{G}, \otimes)$ is an e-hypergroup. Moreover, if $\forall \mathrm{x}, \mathrm{y}$ such that $\mathrm{xy}=\mathrm{e}$, so we have $\mathrm{x} \otimes \mathrm{y}=\mathrm{xy}$, then $(\mathrm{G}, \otimes)$ becomes a strong e-hypergroup.

An application combining hyperstructures and fuzzy theory, is to replace the scale of Likert in questionnaires by the bar of Vougiouklis \& Vougiouklis [41]:

Definition 3.11 In every question substitute the Likert scale with 'the bar' whose poles are defined with ' 0 ' on the left end, and ' 1 ' on the right end:

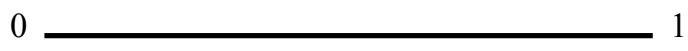

The subjects/participants are asked instead of deciding and checking a specific grade on the scale, to cut the bar at any point they feel expresses their answer to the question.

The use of the bar of Vougiouklis \& Vougiouklis instead of a scale of Likert has several advantages during both the filling-in and the research processing [41]. The suggested length of the bar, according to the Golden Ratio, is $6.2 \mathrm{~cm}$.

\section{References}

[1] R. Bayon, N. Lygeros, Advanced results in enumeration of hyperstructures, J. Algebra, 320, 2008, 821-835.

[2] P. Corsini, V. Leoreanu, Applications of Hypergroup Theory, Kluwer Academic Publ., 2003.

[3] P. Corsini, T. Vougiouklis, From groupoids to groups through hypergroups, Rendiconti Mat. VII, 9, 1989, 173-181.

[4] B. Davvaz, On $\mathrm{H}_{\mathrm{v}}$-subgroups and anti fuzzy $\mathrm{H}_{\mathrm{v}}$-subgroups, Korean J. Comp. Appl. Math. V.5, N.1, 1998, 181-190. 
[5] B. Davvaz, Fuzzy $\mathrm{H}_{\mathrm{v}}$-submodules, Fuzzy sets and Systems, 117 , 2001, 477-484.

[6] B. Davvaz, A brief survey of the theory of $\mathrm{H}_{\mathrm{v}}$-structures, $8^{\text {th }}$ AHA, Greece, Spanidis, 2003, 39-70.

[7] B. Davvaz, W. Dudek, T. Vougiouklis, A generalization of n-ary algebraic systems, Communications in Algebra, 37, 2009, 1248-1263.

[8] B. Davvaz, V. Leoreanu-Fotea, Hyperring Theory and Applications, Int. Academic Press, USA, 2007.

[9] B. Davvaz, R.M. Santilli, T. Vougiouklis, Multi-valued Hypermathematics for characterization of matter and antimatter systems, J. Computational Methods Sciences Eng. 13, 2013, $37-50$.

[10] B. Davvaz, R.M. Santilli, T. Vougiouklis, Mathematical prediction of Ying's twin universes, American J. Modern Physics, 4(3), 2015, 5-9.

[11] B. Davvaz, S. Vougioukli, T. Vougiouklis, On the multiplicative $\mathrm{H}_{\mathrm{v}}$-rings derived from helix hyperoperations, Util. Math., 84, 2011, 53-63.

[12] B. Davvaz, T. Vougiouklis, N-ary hypergroups, Iranian J. of Science \& Technology, Transaction A, V.30, N.A2, 2006, 165-174.

[13] N. Lygeros, T. Vougiouklis, The LV-hyperstructures, Ratio Math., 25, 2013, 59-66.

[14] R.M. Santilli, Hadronic Mathematics, Mechanics and Chemistry, Vol. I, II, III, IV and V, Int. Academic Press, USA, 2008.

[15] R.M. Santilli, T. Vougiouklis, Isotopies, Genotopies, Hyperstructures and their Appl., Proc. New Frontiers in Hyperstructures and Related Algebras, Hadronic, 1996, 1-48.

[16] S. Vougiouklis, $\mathrm{H}_{\mathrm{v}}$-vector spaces from helix hyperoperations, Int. J. Math. Anal. (New Series), 1(2), 2009, 109-120.

[17] T. Vougiouklis, Cyclicity in a special class of hypergroups, Acta Un. Car. - Math. Et Ph., V.22, N1, 1981, 3-6.

[18] T. Vougiouklis, Representations of hypergroups, Hypergroup algebra, Proc. Convegno: ipergrouppi, altre strutture multivoche appl. Udine, 1985, 59-73.

[19] T. Vougiouklis, On affine Kac-Moody Lie algebras, Commentationes Math. Un. Car., V.26, 2, 1985, 387-395

[20] T. Vougiouklis, Representations of hypergroups by hypermatrices, Rivista Mat. Pura Appl., N 2, 1987, 7-19.

[21] T. Vougiouklis, Generalization of P-hypergroups, Rend. Circ. Mat. Palermo, S.II, 36, 1987, 114-121.
[22] T. Vougiouklis, Groups in hypergroups, Annals of Discrete Math. 37, 1988, 459-468

[23] T. Vougiouklis, The fundamental relation in hyperrings. The general hyperfield, Proc. $4^{\text {th }}$ AHA, World Scientific, 1991, 203-211.

[24] T. Vougiouklis, Representations of hypergroups by generalized permutations, Algebra Universalis, 29, 1992, 172-183.

[25] T. Vougiouklis, Representations of $\mathrm{H}_{\mathrm{v}}$-structures, Proc. Int. Conf. Group Theory 1992, Timisoara, 1993, 159-184.

[26] T. Vougiouklis, Hyperstructures and their Representations, Monographs in Math., Hadronic Press, 1994.

[27] T. Vougiouklis, Some remarks on hyperstructures, Contemp. Math., Amer. Math. Society, 184, 1995, 427-431.

[28] T. Vougiouklis, Enlarging $\mathrm{H}_{\mathrm{v}}$-structures, Algebras and Comb., ICAC'97, Hong Kong, Springer-Verlag, 1999, 455-463.

[29] T. Vougiouklis, On $\mathrm{H}_{\mathrm{v}}$-rings and $\mathrm{H}_{\mathrm{v}}$-representations, Discrete Math., Elsevier, 208/209, 1999, 615-620.

[30] T. Vougiouklis, Finite $\mathrm{H}_{\mathrm{v}}$-structures and their representations, Rend. Seminario Mat. Messina S.II, V.9, 2003, 245-265.

[31] T. Vougiouklis, The h/v-structures, J. Discrete Math. Sciences and Cryptography, V.6, 2003, N.2-3, 235-243.

[32] T. Vougiouklis, $\partial$-operations and $\mathrm{H}_{\mathrm{v}}$-fields, Acta Math. Sinica, (Engl. Ser.), V.24, N.7, 2008, 1067-1078.

[33] T. Vougiouklis, The e-hyperstructures, J. Mahani Math. Research Center, V.1, N.1, 2012, 13-28.

[34] T. Vougiouklis, The Lie-hyperalebras and their fundamental relations, Southeast Asian Bull. Math., V.37(4), 2013, 601-614.

[35] T. Vougiouklis, Lie-admissible hyperalgebras, Italian J. Pure Applied Math., N.31, 2013,

[36] T. Vougiouklis, From $\mathrm{H}_{\mathrm{v}}$-rings to $\mathrm{H}_{\mathrm{v}}$-fields, Int. J. Algebraic Hyperstructures Appl. Vol.1, No.1, 2014, 1-13.

[37] T. Vougiouklis, Hypermatrix representations of finite $\mathrm{H}_{\mathrm{v}}$-groups, European J. Combinatorics, V.44 B, 2015, 307-315.

[38] T. Vougiouklis, Quiver of hyperstructures for Ying's twin universes, American J. Modern Physics, 4(1-1), 2015, 30-33.

[39] T. Vougiouklis, S. Vougiouklis, The helix hyperoperations, Italian J. Pure Appl. Math., 18, 2005, 197-206.

[40] T. Vougiouklis, P. Kambaki-Vougioukli, On the use of the bar, China-USA Business Review, V.10, N.6, 2011, 484-489. 